\title{
Factors Associated With Longitudinal QOL Change in Patients With Chronic Liver Diseases
}

\author{
HIROKI NISHIKAWA ${ }^{1,2^{*}}$, KAZUNORI YOH $^{1 *}$, HIRAYUKI ENOMOTO $^{1}$, \\ TAKASHI NISHIMURA ${ }^{1}$, SHUHEI NISHIGUCHI ${ }^{3}$ and HIROKO IIJIMA ${ }^{1}$ \\ ${ }^{1}$ Department of Internal Medicine, Division of Gastroenterology and Hepatology, \\ Hyogo College of Medicine, Nishinomiya, Japan; \\ ${ }^{2}$ Center for Clinical Research and Education, Hyogo College of Medicine, Nishinomiya, Japan; \\ ${ }^{3}$ Kano General Hospital, Osaka, Japan
}

\begin{abstract}
Aim: To examine the relationship between longitudinal quality of life ( $Q O L)$ change, as assessed by the 36-Item Short Form Health Survey (SF-36), sarcopeniarelated factors and body composition in patients with chronic liver diseases (CLDs). Patients and Methods: Data from patients with CLDs ( $n=184)$ were retrospectively analyzed, focusing on factors associated with the difference of physical and mental component summary score (PCS and $M C S)$ in $S F-36$ between the two visits $\left(\triangle_{P C S}\right.$ and $\left.\Delta_{M C S}\right)$. The difference of serum albumin level, body mass index (BMI), arm circumference, arm muscle circumference, grip strength (GS), skeletal muscle index, extracellular to total body water ratio between the two visits were included into the multiple regression analysis. Results: $\Delta_{\text {albumin }}$ $(p=0.0325)$ and $\Delta_{G S}(p<0.0001)$ were independent factors linked to $\Delta_{P C S} . \Delta_{\text {albumin }}(p=0.0005)$ and $\Delta_{B M I}(p=0.0232)$ were independent factors linked to $\Delta_{M C S}$. Conclusion: Significance of serum albumin level, muscle strength and body composition on health-related QOL in CLD patients should be emphasized.
\end{abstract}

Skeletal muscle is an "endocrine organ" that secretes myokines, which regulate glucose and lipid homeostasis throughout the body as well as protein synthesis in muscle

This article is freely accessible online.

*These Authors contributed equally to this work.

Correspondence to: Hiroki Nishikawa, MD, Ph.D., Department of Internal Medicine, Division of Gastroenterology and Hepatology, Hyogo College of Medicine, 1-1, Mukogawacho, Nishinomiyashi, Hyogo 663-8501, Japan. Tel: +81 798456111, Fax: +81 798456608, e-mail: nishikawa_6392_0207@yahoo.co.jp

Key Words: Chronic liver disease, QOL, SF-36, muscle strength, body composition. tissue (1). Sarcopenia is a condition accompanied by decrease of skeletal muscle mass (SMM) and strength or physical function (2, 3). Regarding mechanisms of developing sarcopenia in patients with chronic liver diseases (CLDs), the involvement of numerous factors (aging, protein energy malnutrition, insulin resistance, signal transduction related to SMM protein synthesis and degradation, myokines, and sex hormones, etc.) can be considered (4-6). Sarcopenia can also result in health-related quality of life (QOL) decline and be linked to poor outcomes in CLD patients $(4,7-9)$. The most widely accepted evaluation tool for patient health-related QOL is the 36-Item Short Form Health Survey (SF-36, self-reported questionnaire) (10-12). On the other hand, body composition analysis can be suitable for the evaluation of nutritional status in routine clinical settings as it involves simple and minimally invasive procedures $(13,14)$.

QOL decline in patients with nonalcoholic fatty liver disease was reported to be associated with body composition (15). A decrease in arm circumference (AC) or arm muscle circumference (AMC), which are indicators of hypoalbuminemia and energy deficiency, can adversely affect the prognosis of cirrhotic patients (16). Extracellular water (ECW) to total body water (TBW) ratio (ECW/TBW) using bioelectrical impedance analysis (BIA), which reflects the severity of edematous status in the cell, can reflect the severity of liver fibrosis and be a prognostic marker for cirrhotic patients (17).

In our preceding cross-sectional study, we reported the relationship between sarcopenia-related factors (i.e., muscle strength and muscle mass) and QOL decline in CLD patients (18). However, factors associated with longitudinal QOL change in CLD patients are not largely unknown. To clarify these problems, we sought to examine the relationship between longitudinal QOL change and sarcopenia-related factors and body composition data, in CLD patients. 


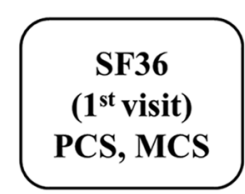

Serum albumin $(\mathrm{g} / \mathrm{dl})$
BMI $\left(\mathrm{kg} / \mathrm{m}^{2}\right)$
AC $(\mathrm{cm})$
AMC $(\mathrm{cm})$
Grip strength $(\mathrm{kg})$
SMI $\left(\mathrm{kg} / \mathrm{m}^{2}\right)$
ECW/TBW

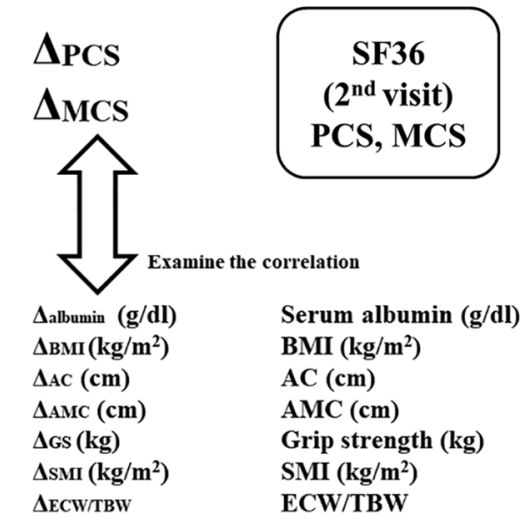

Figure 1. Our study design. PCS, Physical component summary score; MCS, mental component summary score; BMI, body mass index; AC, arm circumference; $A M C$, arm muscle circumference; GS, grip strength; $S M I$, skeletal muscle index; ECW/TBW, extracellular water to total body water ratio. Differences between the two visits (value at second visitvalue at first visit) were calculated for PCS, MCS, serum albumin level,

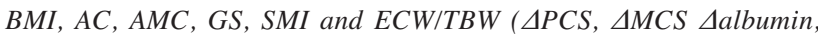
$\triangle B M I, \triangle A C, \triangle A M C, \triangle G S, \triangle S M I$ and $\triangle E C W / T B W$, respectively).

\section{Patients and Methods}

Patients. A total of 184 CLD individuals who visited Hyogo College of Medicine Hospital between December 2013 and April 2018 were analyzed using a retrospective computerized database. All analyzed patients were periodically followed during the observation period. Clinical features, data for SF-36 and body composition and laboratory findings recorded at baseline (first visit for the assessment of QOL using SF-36) and second visit for the assessment of QOL using SF36 were collated. Diagnosis for cirrhosis was determined according to the current guidelines (19). The most suitable intervention for each underlying liver disease was performed (19-22).

$S F-36$. All patients were asked to complete the Japanese version of the SF-36. The Japanese version of the SF-36 is classified into multi-item (eight items) scales: physical functioning, role physical, bodily pain, general health perception, vitality, social functioning, role emotion, and mental health (23). Based on these 8 scales, the physical component summary score (PCS) and the mental component summary score (MCS) were calculated for each patient.

Muscle strength and muscle mass measurement. At first visit and second visit, measurements of muscle strength [grip strength (GS) in this study] and SMM were also performed based on previous reports (3). For the evaluation of SMM, BIA was performed using InBody 720 (InBody Japan 1td., Tokyo, Japan) to calculate appendicular muscle mass. Skeletal muscle index (SMI) was calculated as sum of SMM in upper and lower extremities divided by height squared $\left(\mathrm{kg} / \mathrm{m}^{2}\right)$.

Variables analyzed. The analyzed variables were PCS, MCS, serum albumin level $(\mathrm{g} / \mathrm{dl})$, body mass index (BMI, $\left.\mathrm{kg} / \mathrm{m}^{2}\right), \mathrm{AC}(\mathrm{cm}), \mathrm{AMC}$ $(\mathrm{cm})$, GS $(\mathrm{kg})$, SMI $\left(\mathrm{kg} / \mathrm{m}^{2}\right)$, ECW/TBW in BIA. Differences between the two visits (value at second visit - value at first visit) were calculated for PCS, MCS, serum albumin level, BMI, AC, AMC, GS,
Table I. Baseline characteristics $(n=184)$

\begin{tabular}{lc}
\hline Variables & All cases $(\mathrm{n}=184)$ \\
\hline Age (years) & $62.0 \pm 11.8$ \\
Gender, male/female & $84 / 100$ \\
Liver disease etiology & \\
HCV/HBV/others & $157 / 13 / 14$ \\
Presence of cirrhosis, yes/no & $46 / 138$ \\
Body mass index $\left(\mathrm{kg} / \mathrm{m}^{2}\right)$ & $22.9 \pm 3.4$ \\
SMI $\left(\mathrm{kg} / \mathrm{m}^{2}\right)$, male & $7.6 \pm 0.9$ \\
SMI $\left(\mathrm{kg} / \mathrm{m}^{2}\right)$, female & $5.9 \pm 0.7$ \\
Grip strength $(\mathrm{kg}), \mathrm{male}$ & $36.6 \pm 7.9$ \\
Grip strength $(\mathrm{kg})$, female & $20.3 \pm 4.5$ \\
Arm circumference $(\mathrm{cm})$ & $28.6 \pm 3.1$ \\
Arm muscle circumference $(\mathrm{cm})$ & $23.8 \pm 3.1$ \\
ECW/TBW & $0.390 \pm 0.008$ \\
PCS & $46.7 \pm 12.2$ \\
MCS & $51.9 \pm 9.2$ \\
Total bilirubin $(\mathrm{mg} / \mathrm{dl})$ & $1.0 \pm 0.5$ \\
Serum albumin $(\mathrm{g} / \mathrm{dl})$ & $4.1 \pm 0.4$ \\
Prothrombin time $(\mathrm{INR})$ & $1.1 \pm 0.2$ \\
Platelet count $\left(\times 10^{4} / \mathrm{mm}^{3}\right)$ & $15.9 \pm 6.4$ \\
AST $(\mathrm{IU} / \mathrm{l})$ & $36.0 \pm 24.1$ \\
ALT $(\mathrm{IU} / \mathrm{l})$ & $34.0 \pm 30.2$ \\
eGFR $\left(\mathrm{ml} / \mathrm{min} / 1.73 \mathrm{~m}{ }^{2}\right)$ & $83.0 \pm 20.5$ \\
\end{tabular}

Data are expressed as number or mean value (standard deviation). HCV, Hepatitis C virus; HBV, hepatitis B virus; SMI, skeletal muscle index; ECW, extracellular water; TBW, total body water; PCS, physical component summary score; MCS, mental component summary score; AST, aspartate aminotransferase; ALT, alanine aminotransferase; eGFR, estimated glomerular filtration rate.

SMI and ECW/TBW $\left(\Delta_{\mathrm{PCS}}, \Delta_{\mathrm{MCS}} \Delta_{\text {albumin }}, \Delta_{\mathrm{BMI}}, \Delta_{\mathrm{AC}}, \Delta_{\mathrm{AMC}}, \Delta_{\mathrm{GS}}\right.$, $\Delta_{\mathrm{SMI}}$ and $\Delta_{\mathrm{ECW} / \mathrm{TBW}}$, respectively). Correlation of $\Delta_{\mathrm{PCS}}$ and $\Delta_{\mathrm{MCS}}$ with $\Delta_{\text {albumin }}, \Delta_{\mathrm{BMI}}, \Delta_{\mathrm{AC}}, \Delta_{\mathrm{AMC}}, \Delta_{\mathrm{GS}}, \Delta_{\mathrm{SMI}}$, and $\Delta_{\mathrm{ECW} / \mathrm{TBW}}$ were retrospectively examined. Factors associated with $\Delta_{\mathrm{PCS}}$ and $\Delta_{\mathrm{MCS}}$ were also tested using multiple regression analysis (Figure 1).

The study protocol rigorously conformed to the 1975 Helsinki Declaration, and approval of ethics was obtained from the institutional review board in our hospital (approval number: 2296). An opt out method was employed.

Statistical analysis. Continuous variables were presented as mean value ( \pm standard deviation (SD). Normality was assessed by Shapiro-Wilk test and comparison of continuous variables was performed using the Pearson correlation coefficient $r$. Multivariate regression analysis with multiple predictive factors (least squares method) was used to identify candidate factors. The JMP version 14.0 software (SAS Institute, Cary, NC, USA) was employed to analyze data statistically (significant level, $p$-value below 0.05 ).

\section{Results}

Patient characteristics. Of the 184 CLD patients, 84 (45.7\%) were men, and the mean age was $62.0 \pm 11.8$ years. There were 138 patients $(75.0 \%)$ with non-cirrhosis and 46 patients $(25.0 \%)$ with cirrhosis. There was no patient with overt hepatic 


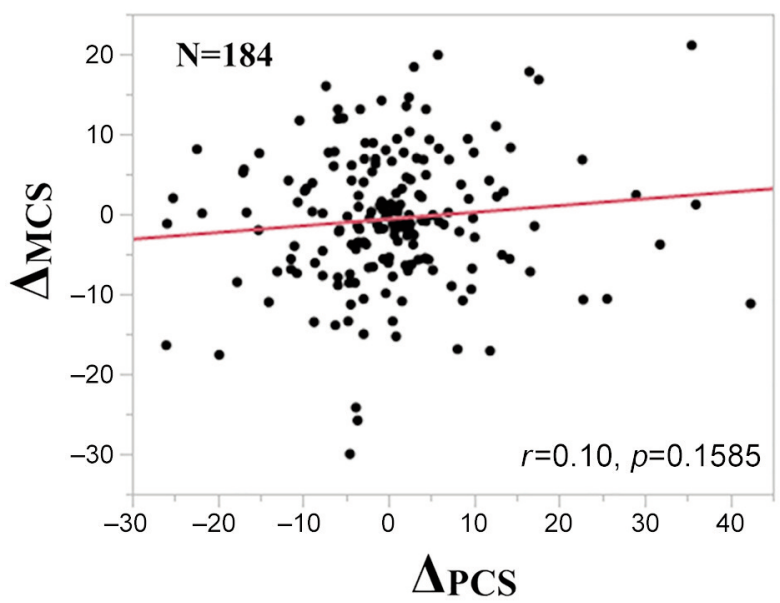

Figure 2. Correlation between $\Delta_{P C S}$ and $\Delta_{M C S}$ for all cases $(n=184)$.

Table II. Correlation of $\Delta_{P C S}$ and $\Delta_{M C S}$ with $\triangle$ albumin, $\Delta_{B M I}, \Delta_{A C}$, $\Delta_{A M C}, \Delta_{G S}, \Delta_{S M I}$ and $\Delta_{E C W / T B W}$ for all cases.

\begin{tabular}{lrrrrr}
\hline All cases & \multicolumn{2}{c}{$\Delta_{\text {PCS }}$} & & \multicolumn{2}{c}{$\Delta_{\text {MCS }}$} \\
\cline { 2 - 3 } \cline { 5 - 6 } & \multicolumn{1}{c}{$\mathrm{r}$} & $p$-Value & & \multicolumn{1}{c}{ r } & $p$-Value \\
\hline$\Delta_{\text {albumin }}$ & 0.28 & 0.0001 & & 0.30 & $<0.0001$ \\
$\Delta_{\text {BMI }}$ & 0.22 & 0.0027 & & 0.16 & 0.0252 \\
$\Delta_{\text {AC }}$ & 0.29 & $<0.0001$ & & 0.08 & 0.2669 \\
$\Delta_{\text {AMC }}$ & -0.05 & 0.5447 & & -0.14 & 0.0621 \\
$\Delta_{\text {GS }}$ & 0.41 & $<0.0001$ & & 0.12 & 0.1091 \\
$\Delta_{\text {SMI }}$ & 0.06 & 0.4287 & & 0.09 & 0.2356 \\
$\Delta_{\text {ECW/TBW }}$ & -0.17 & 0.0230 & -0.08 & 0.2589 \\
\hline
\end{tabular}

$\Delta_{\text {variable }}$, Difference of the variable between the two visits (value at second visit - value at first visit); PCS, physical component summary score; MCS, mental component summary score; BMI, body mass index; AC, arm circumference; AMC, arm muscle circumference; GS, grip strength; SMI, skeletal muscle index; ECW, extracellular water; TBW, total body water.

encephalopathy, hepatocellular carcinoma, or severe ascites at baseline. The main liver disease etiology was hepatitis $\mathrm{C}$ virus (157 cases, $85.3 \%)$. The mean time interval between baseline (first visit) and second visit was $1.2 \pm 1.0$ years. The mean PCS and MCS at baseline were $46.7 \pm 12.2$ and $51.9 \pm 9.2$, respectively. The baseline clinical characteristics and laboratory data of all analyzed patients are summarized in Table I.

Correlation between $\Delta_{P C S}$ and $\Delta_{M C S}$ and $\Delta_{\text {albumin }}, \Delta_{B M I}$, $\Delta_{A C}, \Delta_{A M C}, \Delta_{G S}, \Delta_{S M I}$, and $\Delta_{E C W / T B W}$ for all cases. The mean $\Delta_{\mathrm{PCS}}$ and $\Delta_{\mathrm{MCS}}$ for all cases were $0.4 \pm 10.4$ and $-0.6 \pm 8.4$, respectively. $\Delta_{\mathrm{PCS}}$ did not significantly correlate with $\Delta_{\mathrm{MCS}}(r=0.10, p=0.1585)$ (Figure 2). The mean $\Delta_{\text {albumin }}, \Delta_{\mathrm{BMI}}, \Delta_{\mathrm{AC}}, \Delta_{\mathrm{AMC}}, \Delta_{\mathrm{GS}}, \Delta_{\mathrm{SMI}}$, and $\Delta_{\mathrm{ECW} / \mathrm{TBW}}$ for all cases were $0.1 \pm 0.3 \mathrm{~g} / \mathrm{dl},-0.2 \pm 1.0$
Table III. Correlation of $\Delta_{P C S}$ and $\Delta_{M C S}$ with $\Delta_{\text {albumin }}, \Delta_{B M I}, \Delta_{A C}$, $\Delta_{A M C}, \Delta_{G S}, \Delta_{S M I}$ and $\Delta_{\mathrm{ECW} / \mathrm{TBW}}$ for LC cases and non-LC cases.

\begin{tabular}{|c|c|c|c|c|}
\hline \multirow[t]{2}{*}{$\mathrm{LC}$} & \multicolumn{2}{|c|}{$\Delta_{\mathrm{PCS}}$} & \multicolumn{2}{|c|}{$\Delta_{\mathrm{MCS}}$} \\
\hline & $\mathrm{r}$ & $p$-Value & $\mathrm{r}$ & $p$-Value \\
\hline$\Delta_{\text {albumin }}$ & 0.39 & 0.0074 & 0.49 & 0.0006 \\
\hline$\Delta_{\mathrm{BMI}}$ & 0.08 & 0.6137 & 0.09 & 0.5352 \\
\hline$\Delta_{\mathrm{AC}}$ & 0.34 & 0.0209 & 0.22 & 0.1342 \\
\hline$\Delta_{\mathrm{AMC}}$ & -0.14 & 0.3481 & -0.18 & 0.2227 \\
\hline$\Delta_{\mathrm{GS}}$ & 0.49 & 0.0006 & 0.34 & 0.0212 \\
\hline$\Delta_{\mathrm{SMI}}$ & -0.07 & 0.6316 & 0.01 & 0.9514 \\
\hline$\Delta_{\mathrm{ECW} / \mathrm{TBW}}$ & -0.25 & 0.0882 & -0.17 & 0.2710 \\
\hline \multirow[t]{2}{*}{ Non-LC } & \multicolumn{2}{|c|}{$\Delta_{\mathrm{PCS}}$} & \multicolumn{2}{|c|}{$\Delta_{\mathrm{MCS}}$} \\
\hline & $\mathrm{r}$ & $p$-Value & $\mathrm{r}$ & $p$-Value \\
\hline$\Delta_{\text {albumin }}$ & 0.17 & 0.0494 & 0.21 & 0.0118 \\
\hline$\Delta_{\mathrm{BMI}}$ & 0.27 & 0.0013 & 0.18 & 0.032 \\
\hline$\Delta_{\mathrm{AC}}$ & 0.24 & 0.0041 & 0.02 & 0.8100 \\
\hline$\Delta_{\mathrm{AMC}}$ & 0.00 & 0.9804 & -0.12 & 0.1530 \\
\hline$\Delta_{\mathrm{GS}}$ & 0.35 & $<0.0001$ & 0.03 & 0.7563 \\
\hline$\Delta_{\mathrm{SMI}}$ & 0.18 & 0.0313 & 0.14 & 0.0944 \\
\hline$\Delta_{\mathrm{ECW} / \mathrm{TBW}}$ & -0.07 & 0.4489 & -0.03 & 0.7259 \\
\hline
\end{tabular}

$\Delta_{\text {variable }}$, Difference of the variable between the two visits (value at second visit - value at first visit); PCS, physical component summary score; MCS, mental component summary score; BMI, body mass index; AC, arm circumference; AMC, arm muscle circumference; GS, grip strength; SMI, skeletal muscle index; ECW, extracellular water; TBW, total body water.

$\mathrm{kg} / \mathrm{m}^{2},-0.2 \pm 1.1 \mathrm{~cm},-1.3 \pm 1.9 \mathrm{~cm},-0.1 \pm 3.1 \mathrm{~kg},-0.03 \pm 0.28$ $\mathrm{kg} / \mathrm{m}^{2}$, and $0.0003 \pm 0.005$, respectively.

$\Delta_{\text {albumin }}(r=0.28, p=0.0001), \Delta_{\mathrm{BMI}}(r=0.22, p=0.0027)$, $\Delta_{\mathrm{AC}}(r=0.29, p<0.0001), \Delta_{\mathrm{GS}}(r=0.41, p<0.0001)$, and $\Delta_{\text {ECW/TBW }}(r=-0.17, p=0.0230)$ significantly correlated with $\Delta_{\text {PCS }} \cdot \Delta_{\text {albumin }}(r=0.30, p<0.0001)$ and $\Delta_{\text {BMI }}(r=0.16$, $p=0.0252$ ) had significant correlation with $\Delta_{\text {MCS }}$ (Table II).

Correlation between $\triangle_{P C S}$ and $\triangle_{M C S}$ and $\triangle_{\text {albumin }}, \Delta_{B M I}$, $\Delta_{A C}, \Delta_{A M C}, \Delta_{G S}, \Delta_{S M I}$, and $\Delta_{E C W / T B W}$ for liver cirrhosis (LC) cases $(n=46)$. The mean $\Delta_{\mathrm{PCS}}$ and $\Delta_{\mathrm{MCS}}$ for LC cases were $2.8 \pm 13.0$ and $0.3 \pm 8.1$, respectively. The mean $\Delta_{\text {albumin }}$, $\Delta_{\mathrm{BMI}}, \Delta_{\mathrm{AC}}, \Delta_{\mathrm{AMC}}, \Delta_{\mathrm{GS}}, \Delta_{\mathrm{SMI}}$, and $\Delta_{\mathrm{ECW} / \mathrm{TBW}}$ for LC cases were $0.2 \pm 0.4 \mathrm{~g} / \mathrm{dl}, 0.2 \pm 1.2 \mathrm{~kg} / \mathrm{m}^{2}, 0.1 \pm 1.2 \mathrm{~cm},-1.4 \pm 1.8 \mathrm{~cm}$, $0.4 \pm 3.6 \mathrm{~kg},-0.1 \pm 0.4 \mathrm{~kg} / \mathrm{m}^{2}$, and $-0.001 \pm 0.006$, respectively.

$\Delta_{\text {albumin }}(r=0.39, p=0.0074), \Delta_{\mathrm{AC}}(r=0.34, p=0.0209)$, and $\Delta_{\mathrm{GS}}(r=0.49, p=0.0006)$ significantly correlated with $\Delta_{\mathrm{PCS}}$. $\Delta_{\text {albumin }}(r=0.49, p=0.0006)$ and $\Delta_{\mathrm{GS}}(r=0.34, p=0.0212)$ had significant correlation with $\Delta_{\mathrm{MCS}}$ (Table III).

Correlation between $\Delta_{P C S}$ and $\Delta_{M C S}$ and $\Delta_{\text {albumin }}, \Delta_{B M I}$, $\Delta_{A C}, \Delta_{A M C}, \Delta_{G S}, \Delta_{S M I}$, and $\Delta_{E C W / T B W}$ for non-LC cases $(n=138)$. The mean $\Delta_{\mathrm{PCS}}$ and $\Delta_{\mathrm{MCS}}$ for non-LC cases 
Table IV. Correlation of $\Delta_{P C S}$ and $\Delta_{M C S}$ with $\Delta_{\text {albumin }}, \Delta_{A C}, \Delta_{A M C}$ $\Delta_{G S}, \Delta_{S M I}$ and $\Delta_{\mathrm{ECW} / \mathrm{TBW}}$ for LC male and female.

\begin{tabular}{lrrrrr}
\hline Male & \multicolumn{2}{c}{$\Delta_{\text {PCS }}$} & & \multicolumn{2}{c}{$\Delta_{\text {MCS }}$} \\
\cline { 2 - 3 } \cline { 5 - 6 } & \multicolumn{1}{c}{$r$} & $p$-Value & & $r$ & $p$-Value \\
\hline$\Delta_{\text {albumin }}$ & 0.30 & 0.0048 & & 0.28 & 0.0100 \\
$\Delta_{\text {BMI }}$ & 0.20 & 0.0635 & & 0.21 & 0.0604 \\
$\Delta_{\text {AC }}$ & 0.25 & 0.0201 & & 0.04 & 0.7126 \\
$\Delta_{\text {AMC }}$ & -0.04 & 0.7091 & & -0.02 & 0.8314 \\
$\Delta_{\text {GS }}$ & 0.40 & 0.0002 & & -0.01 & 0.9603 \\
$\Delta_{\text {SMI }}$ & -0.19 & 0.0808 & & 0.05 & 0.6206 \\
$\Delta_{\text {ECW/TBW }}$ & -0.18 & 0.0993 & & -0.09 & 0.4122 \\
\hline
\end{tabular}

\begin{tabular}{lrrrrr}
\hline \multirow{2}{*}{ Female } & \multicolumn{2}{c}{$\Delta_{\text {PCS }}$} & & \multicolumn{2}{c}{$\Delta_{\text {MCS }}$} \\
\cline { 2 - 3 } \cline { 5 - 6 } & \multicolumn{1}{c}{$\mathrm{r}$} & $p$-Value & & \multicolumn{1}{c}{$\mathrm{r}$} & $p$-Value \\
\hline$\Delta_{\text {albumin }}$ & 0.26 & 0.0091 & & 0.31 & 0.0017 \\
$\Delta_{\text {BMI }}$ & 0.25 & 0.0135 & & 0.15 & 0.1314 \\
$\Delta_{\text {AC }}$ & 0.31 & 0.0014 & & 0.11 & 0.2668 \\
$\Delta_{\text {AMC }}$ & -0.04 & 0.6927 & & -0.21 & 0.0360 \\
$\Delta_{\text {GS }}$ & 0.43 & $<0.0001$ & & 0.24 & 0.0182 \\
$\Delta_{\text {SMI }}$ & 0.24 & 0.0169 & & 0.12 & 0.2478 \\
$\Delta_{\text {ECW/TBW }}$ & -0.16 & 0.1018 & -0.08 & 0.4578
\end{tabular}

$\Delta_{\text {variable }}$, Difference of the variable between the two visits (value at second visit - value at first visit); PCS; physical component summary score, MCS; mental component summary score, BMI; body mass index, AC; arm circumference, AMC; arm muscle circumference, GS; grip strength, SMI; skeletal muscle index, ECW; extracellular water, TBW; total body water.

were $-0.4 \pm 9.3$ and $-0.9 \pm 8.5$, respectively. The mean $\Delta_{\text {albumin, }}$ $\Delta_{\mathrm{BMI}}, \Delta_{\mathrm{AC}}, \Delta_{\mathrm{AMC}}, \Delta_{\mathrm{GS}}, \Delta_{\mathrm{SMI}}$, and $\Delta_{\mathrm{ECW} / \mathrm{TBW}}$ for non-LC cases were $0.03 \pm 0.28 \mathrm{~g} / \mathrm{dl},-0.3 \pm 1.0 \mathrm{~kg} / \mathrm{m}^{2},-0.3 \pm 1.1$ $\mathrm{cm},-1.3 \pm 1.9 \mathrm{~cm},-0.3 \pm 2.9 \mathrm{~kg},-0.01 \pm 0.23 \mathrm{~kg} / \mathrm{m}^{2}$, and $0.0008 \pm 0.004$, respectively.

$\Delta_{\text {albumin }}(r=0.17, p=0.0494), \Delta_{\mathrm{BMI}}(r=0.27, p=0.0013)$, $\Delta_{\mathrm{AC}}(r=0.24, p=0.0041), \Delta_{\mathrm{GS}}(r=0.35, p<0.0001)$, and $\Delta_{\mathrm{SMI}}$ $(r=-0.18, p=0.0313)$ significantly correlated with $\Delta_{\mathrm{PCS}}$. $\Delta_{\text {albumin }}(r=0.21, p=0.0118)$ and $\Delta_{\mathrm{BMI}}(r=0.18, p=0.0320)$ had significant correlation with $\Delta_{\mathrm{MCS}}$ (Table III).

Correlation between $\triangle_{P C S}$ and $\Delta_{M C S}$ and $\Delta_{\text {albumin }}, \Delta_{B M I}$, $\Delta_{A C}, \Delta_{A M C}, \Delta_{G S}, \Delta_{S M I}$, and $\Delta_{E C W / T B W}$ for male cases $(n=84)$. The mean $\Delta_{\mathrm{PCS}}$ and $\Delta_{\mathrm{MCS}}$ for male cases were $-0.4 \pm 8.9$ and $-1.2 \pm 8.1$, respectively. The mean $\Delta_{\text {albumin }}, \Delta_{\mathrm{BMI}}, \Delta_{\mathrm{AC}}, \Delta_{\mathrm{AMC}}, \Delta_{\mathrm{GS}}, \Delta_{\mathrm{SMI}}$, and $\Delta_{\mathrm{ECW} / \mathrm{TBW}}$ for male cases were $0 \pm 0.34 \mathrm{~g} / \mathrm{dl},-0.03 \pm 1.0 \mathrm{~kg} / \mathrm{m}^{2},-0.3 \pm 1.1$ $\mathrm{cm},-1.2 \pm 1.7 \mathrm{~cm},-0.2 \pm 3.5 \mathrm{~kg},-0.03 \pm 0.29\left(\mathrm{~kg} / \mathrm{m}^{2}\right)$, and $0.0004 \pm 0.005$, respectively.

$\Delta_{\text {albumin }}(r=0.30, p=0.0048), \Delta_{\mathrm{AC}}(r=0.25, p=0.0201)$, and $\Delta_{\mathrm{GS}}(r=0.40, p=0.0002)$ significantly correlated with $\Delta_{\mathrm{PCS}}$. $\Delta_{\text {albumin }}(r=0.28, p=0.010)$ had significant correlation with $\Delta_{\text {MCS }}$ (Table IV).
Table V. Multiple regression analysis linked to $\Delta_{P C S}$ and $\Delta_{M C S}$.

\begin{tabular}{lccr}
\hline$\Delta_{\text {PCS }}$ & Estimates & Standard error & $p$-Value \\
\hline$\Delta_{\text {albumin }}$ & 4.884 & 2.266 & 0.0325 \\
$\Delta_{\text {BMI }}$ & 0.239 & 1.241 & 0.8476 \\
$\Delta_{\text {AC }}$ & 1.596 & 1.091 & 0.1454 \\
$\Delta_{\text {AMC }}$ & -0.137 & 0.388 & 0.7247 \\
$\Delta_{\text {GS }}$ & 1.039 & 0.252 & $<0.0001$ \\
$\Delta_{\text {SMI }}$ & -1.889 & 3.400 & 0.5792 \\
$\Delta_{\text {ECW/TBW }}$ & 95.487 & 197.064 & 0.6286 \\
\hline$\Delta_{\text {MCS }}$ & Estimates & Standard error & $p$-Value \\
\hline$\Delta_{\text {albumin }}$ & 6.855 & 1.922 & 0.0005 \\
$\Delta_{\text {BMI }}$ & 2.41 & 1.052 & 0.0232 \\
$\Delta_{\text {AC }}$ & -1.64 & 0.925 & 0.0781 \\
$\Delta_{\text {AMC }}$ & -0.426 & 0.329 & 0.1977 \\
$\Delta_{\text {GS }}$ & 0.013 & 0.214 & 0.9501 \\
$\Delta_{\text {SMI }}$ & 1.425 & 2.883 & 0.6218 \\
$\Delta_{\text {ECW/TBW }}$ & -116.245 & 167.087 & 0.4875 \\
\hline
\end{tabular}

$\Delta_{\text {variable }}$, Difference of the variable between the two visits (value at second visit - value at first visit); PCS, physical component summary score; MCS, mental component summary score; BMI, body mass index; AC, arm circumference; AMC, arm muscle circumference; GS, grip strength; SMI, skeletal muscle index; ECW, extracellular water; TBW, total body water.

Correlation between $\triangle_{P C S}$ and $\Delta_{M C S}$ and $\Delta_{\text {albumin }}, \Delta_{B M I}, \Delta_{A C}$, $\Delta_{A M C}, \Delta_{G S}, \Delta_{S M I}$, and $\Delta_{E C W / T B W}$ for female cases $(n=100)$. The mean $( \pm \mathrm{SD}) \Delta_{\mathrm{PCS}}$ and $\Delta_{\mathrm{MCS}}$ for female cases were 1.0 011.5 and $0 \pm 8.6$, respectively. The mean $( \pm \mathrm{SD}) \Delta_{\text {albumin }}, \Delta_{\mathrm{BMI}}, \Delta_{\mathrm{AC}}$, $\Delta_{\mathrm{AMC}}, \Delta_{\mathrm{GS}}, \Delta_{\mathrm{SMI}}$, and $\Delta_{\mathrm{ECW} / \mathrm{TBW}}$ for female cases were $0.1 \pm 0.32 \mathrm{~g} / \mathrm{dl},-0.3 \pm 1.1 \mathrm{~kg} / \mathrm{m}^{2},-0.2 \pm 1.1 \mathrm{~cm},-1.4 \pm 2.0 \mathrm{~cm}, 0 \pm 2.8$ $\mathrm{kg},-0.03 \pm 0.27 \mathrm{~kg} / \mathrm{m}^{2}$, and $0.0002 \pm 0.004$, respectively.

$\Delta_{\text {albumin }}(r=0.26, p=0.0091), \Delta_{\mathrm{BMI}}(r=0.25, p=0.0135)$, $\Delta_{\mathrm{AC}}(r=0.31, p=0.0014), \Delta_{\mathrm{GS}}(r=0.43, p<0.0001)$, and $\Delta_{\mathrm{SMI}}$ $(r=0.24, p=0.0169)$ significantly correlated with $\Delta_{\text {PCS }}$. $\Delta_{\text {albumin }}(r=0.31, p=0.0017)$ and $\Delta_{\text {AMC }}(r=-0.21, p=0.0360)$ had significant correlation with $\Delta_{\mathrm{MCS}}$ (Table IV).

Multiple regression analysis linked to $\triangle_{P C S}$ and $\triangle_{M C S}$ for all cases. Results for multiple regression analysis associated with $\Delta_{\mathrm{PCS}}$ and $\Delta_{\mathrm{MCS}}$ are shown in Table V. $\Delta_{\text {albumin }}$ $(p=0.0325)$ and $\Delta_{\mathrm{GS}}(p<0.0001)$ were independent factors linked to $\Delta_{\mathrm{PCS}} \cdot \Delta_{\text {albumin }}(p=0.0005)$ and $\Delta_{\mathrm{BMI}}(p=0.0232)$ were independent factors linked to $\Delta_{\mathrm{MCS}}$.

\section{Discussion}

In 1946, the WHO proposed that "health indicates a state of very good and stable physical, psychological and social well-being and not merely the absence of disease" (18). By recent years, there have been changes in the medical and social context, such as changes in the structure of diseases, the achievement of longevity, and a re-evaluation of the value of living well. In this 
context, the concept of health-related QOL has developed and gained importance as a goal of treatment and care. QOL improvement is now an indispensable perspective in the medical and health care fields. As far as we are aware, longitudinal studies in CLD patients focusing on sarcopenia-related factors and body composition in QOL research are rare. As CLD generally involves long disease duration and a lot of liver disease-related events are expected to occur during the clinical course, this study focusing on changes of QOL is considered to be of clinical importance. In CLD patients, hepatic events or severity of liver fibrosis as well as aging can be associated with QOL decline (24). However, in our data, $\Delta_{\mathrm{PCS}}$ did not significantly correlate with $\Delta_{\mathrm{MCS}}(r=0.10)$. Factors linked to $\Delta_{\mathrm{PCS}}$ and $\Delta_{\mathrm{MCS}}$ should be therefore analyzed separately. There were 92 patients $(50.0 \%)$ with $\Delta_{\mathrm{PCS}}>0$ and 85 patients $(46.2 \%)$ with $\Delta_{\mathrm{MCS}}>0$ in our data. Various interventions for underlying liver diseases were done in our cohort, and appropriate interventions may improve QOL in CLD patients.

In the current study, comprehensive analyses regarding the impact of sarcopenia-related factors and body composition data on the longitudinal QOL change in patients with CLDs were performed. Multiple regression analysis identified $\Delta_{\text {albumin }}$ and $\Delta_{\mathrm{GS}}$ as significant factors linked to $\Delta_{\mathrm{PCS}}$, and $\Delta_{\text {albumin }}$ and $\Delta_{\text {BMI }}$ as significant factors linked to $\Delta_{\text {MCS }}$. To conclude, a decline of serum albumin level can be helpful for QOL decline both physically and mentally, and reduced GS rather than SMM can be linked to physical QOL decline, while reduced BMI can result in mental QOL decline in CLD patients. Serum albumin level, GS, and BMI can be easily obtained in daily clinical practice. Thus, our results appear to be clinically meaningful, and when these markers worsen in CLD patients, clinicians should be aware of QOL decline. On the other hand, AC reflects SMM and fat mass, while AMC reflects SMM (16). Both markers were not significant in multiple regression analysis, however, $\Delta_{\mathrm{AC}}$ significantly correlated with $\Delta_{\mathrm{PCS}}$ for all cases and for all subgroups in the univariate analysis. Hence, anthropometric assessment in CLD patients can be essential for the change of physical condition.

It is unclear why the decline of muscle strength can better predict the exacerbation of physical QOL in patients with CLDs, compared to SMM decline. One possible reason is that muscle strength decline occurs 2-5 times faster than SMM loss, which can be linked to the physical QOL decline (25). Another possible reason is that muscle strength decline is associated with hormonal changes such as insulin-like growth factors 1 and testosterone, potentially resulting in exacerbation of physical condition (26). GS can be a representative marker for whole-body muscle strength and has been shown to be an independent marker of nutrition (27). However, in non-LC patients and in female patients, $\Delta_{\mathrm{SMI}}$ significantly correlated with $\Delta_{\mathrm{PCS}}$. While the present study emphasizes the importance of GS on the deterioration of physical condition, it does not deny the importance of SMM on physical QOL.
The limitations of our study must be acknowledged. First, the retrospective nature of the study limits the evaluation of factors influencing QOL such as life circumstances. Second, SF-36 is a subjective assessment tool, and not objective one, and CLDQ questionnaires specific to QOL in CLD patients were not used in this study (28). Third, our data were based on Japanese CLD patient data; further studies on other cohorts will be needed to extend the application. Finally, several interventions for CLD patients in the observation period have been performed, creating bias for QOL decline. Thus, interpretation with caution to the results will be needed. However, our results denoted that chronological decline of serum albumin or GS was associated with a decline in physical QOL and chronological decline of serum albumin or BMI was associated with a decline in mental QOL.

In conclusion, decreased serum albumin level, muscle strength decline and poor body composition can be associated with QOL decline in CLD patients. Therefore, we would like to emphasize the significance of these factors in health-related QOL in CLD patients.

\section{Conflicts of Interest}

Nothing to declare.

\section{Authors' Contributions}

Data curation, H.N., K.Y., H.E., and T.N.; Formal analysis, H.N.; Supervision, S.N. and H.I.; Writing - original draft, H.N. and K.Y.; Writing - review \& editing, H.E.; Final approval, all authors.

\section{Acknowledgements}

The Authors would like to thank Yasuko Higuchi in our hospital for the anthropometry measurement. This work was partly supported by Hyogo Innovative Challenge, Hyogo College of Medicine, Japan.

\section{References}

1 Li F, Li Y, Duan Y, Hu CA, Tang Y and Yin Y: Myokines and adipokines: Involvement in the crosstalk between skeletal muscle and adipose tissue. Cytokine Growth Factor Rev 33: 73 82, 2017. PMID: 27765498. DOI: 10.1016/j.cytogfr.2016.10.003

2 Cruz-Jentoft AJ, Bahat G, Bauer J, Boirie Y, Bruyère O, Cederholm T, Cooper C, Landi F, Rolland Y, Sayer AA, Schneider SM, Sieber CC, Topinkova E, Vandewoude M, Visser M, Zamboni $\mathrm{M}$ and Writing Group for the European Working Group on Sarcopenia in Older People 2 (EWGSOP2) and the Extended Group for EWGSOP2: Sarcopenia: revised European consensus on definition and diagnosis. Age Ageing 48(1): 1631, 2019. PMID: 30312372. DOI: 10.1093/ageing/afy169

3 Nishikawa H, Shiraki M, Hiramatsu A, Moriya K, Hino K and Nishiguchi S: Japan Society of Hepatology guidelines for sarcopenia in liver disease (1st edition): Recommendation from the working group for creation of sarcopenia assessment criteria. Hepatol Res 46(10): 951-963, 2016. PMID: 27481650. DOI: 10.1111/hepr.12774 
4 Sinclair M, Gow PJ, Grossmann M and Angus PW: Review article: sarcopenia in cirrhosis-aetiology, implications and potential therapeutic interventions. Aliment Pharmacol Ther 43(7): 765-777, 2016. PMID: 26847265. DOI: 10.1111/apt.13549

5 Nishikawa H, Enomoto H, Ishii A, Iwata Y, Miyamoto Y, Ishii N, Yuri Y, Hasegawa K, Nakano C, Nishimura T, Yoh K, Aizawa N, Sakai Y, Ikeda N, Takashima T, Takata R, Iijima H and Nishiguchi $\mathrm{S}$ : Elevated serum myostatin level is associated with worse survival in patients with liver cirrhosis. J Cachexia Sarcopenia Muscle 8(6): 915-925, 2017. PMID: 28627027. DOI: 10.1002/jcsm.12212

6 Dasarathy S: Myostatin and beyond in cirrhosis: all roads lead to sarcopenia. J Cachexia Sarcopenia Muscle 8(6): 864-869, 2017. PMID: 29168629. DOI: $10.1002 /$ jcsm.12262

7 Hsu CS and Kao JH: Sarcopenia and chronic liver diseases. Expert Rev Gastroenterol Hepatol 12(12): 1229-1244, 2018. PMID: 30791794. DOI: 10.1080/17474124.2018.1534586

8 Nishikawa $\mathrm{H}$, Enomoto $\mathrm{H}$, Nishiguchi $\mathrm{S}$ and Iijima $\mathrm{H}$ : Liver cirrhosis and sarcopenia from the viewpoint of dysbiosis. Int $\mathrm{J}$ Mol Sci 21(15): 5254, 2020. PMID: 32722100. DOI: 10.3390/ ijms21155254

9 Bunchorntavakul C and Reddy KR: Review article: malnutrition/ sarcopenia and frailty in patients with cirrhosis. Aliment Pharmacol Ther 51(1): 64-77, 2020. PMID: 31701570. DOI: 10.1111/apt.15571

10 Beaudart C, Biver E, Bruyère O, Cooper C, Al-Daghri N, Reginster JY and Rizzoli R: Quality of life assessment in musculo-skeletal health. Aging Clin Exp Res 30(5): 413-418, 2018. PMID: 28664458. DOI: 10.1007/s40520-017-0794-8

11 Crawford B, Yeung CK, Tanaka E, Kraemer M and Leteneux C: Hepatitis C virus in Asia: utility values based on the Short Form36 questionnaire. Expert Rev Pharmacoecon Outcomes Res 12(6): 765-773, 2012. PMID: 23252358. DOI: 10.1586/erp.12.61

12 Younossi ZM, Golabi P and Henry L: A comprehensive review of patient-reported outcomes in patients with chronic liver diseases. J Clin Gastroenterol 53(5): 331-341, 2019. PMID: 30702486. DOI: 10.1097/MCG.0000000000001179

13 Smith S and Madden AM: Body composition and functional assessment of nutritional status in adults: a narrative review of imaging, impedance, strength and functional techniques. J Hum Nutr Diet 29(6): 714-732, 2016. PMID: 27137882. DOI: $10.1111 /$ jhn. 12372

14 Utkualp N and Ercan I: Anthropometric measurements usage in medical sciences. Biomed Res Int 2015: 404261, 2015. PMID: 26413519. DOI: $10.1155 / 2015 / 404261$

15 Samala N, Desai A, Vilar-Gomez E, Smith ER, Gawrieh S, Kettler CD, Pike F and Chalasani N: Decreased quality of life is significantly associated with body composition in patients with nonalcoholic fatty liver disease. Clin Gastroenterol Hepatol 18(13): 2980-2988.e4, 2020. PMID: 32360826. DOI: 10.1016/ j.cgh.2020.04.046

16 Moriwaki EI, Enomoto H, Saito M, Hara N, Nishikawa H, Nishimura $\mathrm{T}$, Iwata $\mathrm{Y}$, Iijima $\mathrm{H}$ and Nishiguchi $\mathrm{S}$ : The anthropometric assessment with the bioimpedance method is associated with the prognosis of cirrhotic patients. In Vivo 34(2): 687-693, 2020. PMID: 32111771. DOI: 10.21873/invivo.11825

17 Kishino K, Enomoto H, Shimono Y, Moriwaki EI, Nishikawa H, Nishimura T, Iwata Y, Iijima $\mathrm{H}$ and Nishiguchi S: Association of an overhydrated state with the liver fibrosis and prognosis of cirrhotic patients. In Vivo 34(3): 1347-1353, 2020. PMID: 32354929. DOI: 10.21873/invivo.11912
18 Nishikawa H, Enomoto H, Yoh K, Iwata Y, Sakai Y, Kishino K, Ikeda N, Takashima T, Aizawa N, Takata R, Hasegawa K, Ishii $\mathrm{N}$, Yuri $\mathrm{Y}$, Nishimura T, Iijima $\mathrm{H}$ and Nishiguchi S: Healthrelated quality of life in chronic liver diseases: a strong impact of hand grip strength. J Clin Med 7(12): 553, 2018. PMID: 30558298. DOI: $10.3390 / \mathrm{jcm} 7120553$

19 Fukui H, Saito H, Ueno Y, Uto H, Obara K, Sakaida I, Shibuya A, Seike M, Nagoshi S, Segawa M, Tsubouchi H, Moriwaki H, Kato A, Hashimoto E, Michitaka K, Murawaki T, Sugano K, Watanabe $\mathrm{M}$ and Shimosegawa T: Evidence-based clinical practice guidelines for liver cirrhosis 2015. J Gastroenterol 51(7): 629-650, 2016. PMID: 27246107. DOI: 10.1007/s00535-016-1216-y

20 European Association for the Study of the Liver: EASL recommendations on treatment of hepatitis C 2018. J Hepatol 69(2): 461-511, 2018. PMID: 29650333. DOI: 10.1016/j.jhep.2 018.03 .026

21 Kokudo N, Takemura N, Hasegawa K, Takayama T, Kubo S, Shimada M, Nagano H, Hatano E, Izumi N, Kaneko S, Kudo M, Iijima H, Genda T, Tateishi R, Torimura T, Igaki H, Kobayashi S, Sakurai H, Murakami T, Watadani T and Matsuyama Y: Clinical practice guidelines for hepatocellular carcinoma: The Japan Society of Hepatology 2017 (4th JSH-HCC guidelines) 2019 update. Hepatol Res 49(10): 1109-1113, 2019. PMID: 31336394. DOI: 10.1111/hepr.13411

22 Drafting Committee for Hepatitis Management Guidelines, the Japan Society of Hepatology: Japan Society of Hepatology guidelines for the management of hepatitis B virus infection: 2019 update. Hepatol Res 50(8): 892-923, 2020. PMID: 32343469. DOI: 10.1111/hepr.13504

23 Fukuhara S, Ware JE Jr, Kosinski M, Wada S and Gandek B: Psychometric and clinical tests of validity of the Japanese SF36 Health Survey. J Clin Epidemiol 51(11): 1045-1053, 1998. PMID: 9817122. DOI: 10.1016/s0895-4356(98)00096-1

24 Peng JK, Hepgul N, Higginson IJ and Gao W: Symptom prevalence and quality of life of patients with end-stage liver disease: A systematic review and meta-analysis. Palliat Med 33(1): 24-36, 2019. PMID: 30345878. DOI: 10.1177/0269216318807051

25 Hanai T, Shiraki M, Imai K, Suetsugu A, Takai K, Moriwaki H and Shimizu M: Reduced handgrip strength is predictive of poor survival among patients with liver cirrhosis: A sex-stratified analysis. Hepatol Res 49(12): 1414-1426, 2019. PMID: 31408558. DOI: $10.1111 /$ hepr.13420

26 Dattilo M, Antunes HK, Medeiros A, Mônico Neto M, Souza HS, Tufik S and de Mello MT: Sleep and muscle recovery: endocrinological and molecular basis for a new and promising hypothesis. Med Hypotheses 77(2): 220-222, 2011. PMID: 21550729. DOI: 10.1016/j.mehy.2011.04.017

27 Flood A, Chung A, Parker H, Kearns V and O'Sullivan TA: The use of hand grip strength as a predictor of nutrition status in hospital patients. Clin Nutr 33(1): 106-114, 2014. PMID: 23615623. DOI: 10.1016/j.clnu.2013.03.003

28 Janani K, Jain M, Vargese J, Srinivasan V, Harika K, Michael T and Venkataraman J: Health-related quality of life in liver cirrhosis patients using SF-36 and CLDQ questionnaires. Clin Exp Hepatol 4(4): 232-239, 2018. PMID: 30603670. DOI: $10.5114 /$ ceh.2018.80124

Received January 29, 2021

Revised April 12, 2021

Accepted April 19, 2021 